\title{
Allometry Between Vegetative and Reproductive Traits in Orchids
}

\author{
Jing-Qiu Feng ${ }^{1,2}$, Feng-Ping Zhang ${ }^{3 *}$, Jia-Lin Huang ${ }^{4}$, Hong Hu ${ }^{1}$ and Shi-Bao Zhang ${ }^{1 *}$ \\ ${ }^{1}$ Key Laboratory of Economic Plants and Biotechnology, Yunnan Key Laboratory for Wild Plant Resources, Kunming Institute \\ of Botany, Chinese Academy of Sciences, Kunming, China, 'University of Chinese Academy of Sciences, Beijing, China, \\ ${ }^{3}$ Yunnan Key Laboratory of Dai and Yi Medicines, College of Traditional Chinese Medicine, Yunnan University of Chinese \\ Medicine, Kunming, China, ${ }^{4}$ Yuxi Normal University, Yuxi, China
}

OPEN ACCESS

Edited by:

Edwige Moyroud, University of Cambridge,

United Kingdom

Reviewed by:

Miho Stephanie Kitazawa,

Osaka University, Japan

Marie Monniaux,

UMR5667 Laboratoire Reproduction et Développement des Plantes (RDP),

France

*Correspondence:

Feng-Ping Zhang

zhangfengping8008@163.com

Shi-Bao Zhang

sbzhang@mail.kib.ac.cn

Specialty section:

This article was submitted to

Plant Development and EvoDevo,

a section of the journal

Frontiers in Plant Science

Received: 22 June 2021

Accepted: 25 August 2021

Published: 13 October 2021

Citation:

Feng J-Q, Zhang F-P, Huang J-L,

Hu $H$ and Zhang S-B (2021)

Allometry Between Vegetative and Reproductive Traits in Orchids.

Front. Plant Sci. 12:728843.

doi: 10.3389/fpls.2021.728843
In flowering plants, inflorescence characteristics influence both seed set and pollen contribution, while inflorescence and peduncle size can be correlated with biomass allocation to reproductive organs. Peduncles also play a role in water and nutrient supply of flowers, and mechanical support. However, it is currently unclear whether inflorescence size is correlated with peduncle size. Here, we tested whether orchids with large diameter peduncles bear more and larger flowers than those with smaller peduncles by analyzing 10 traits of inflorescence, flower, and leaf in 26 species. Peduncle diameters were positively correlated with inflorescence length and total floral area, indicating that species with larger peduncles tended to have larger inflorescences and larger flowers. We also found strongly positive correlation between inflorescence length and leaf area, and between total floral area and total leaf area, which suggested that reproductive organs may be allometrically coordinated with vegetative organs. However, neither flower number nor floral dry mass per unit area were correlated with leaf number or leaf dry mass per unit area, implying that the function between leaf and flower was uncoupled. Our findings provided a new insight for understanding the evolution of orchids, and for horticulturalists interested in improving floral and inflorescence traits in orchids.

Keywords: allometry, flower traits, inflorescence length, orchids, peduncle diameter, leaf traits

\section{INTRODUCTION}

Floral display, which includes floral number, size, color, and arrangement, has a central influence on plant reproductive success (Harder and Johnson, 2005; Iwata et al., 2012). Plants with larger inflorescences and flowers receive generally more pollinator visits and increased reproductive success (Pleasants and Zimmerman, 1990; Harder and Johnson, 2005). Not surprisingly, the functional and evolutionary significance of flower and inflorescence sizes are subjects of strong interest (Darwin, 1859; Grant, 1950; Wyatt, 1982; Armbruster, 1996; Galen et al., 1999; Elle, 2004; Fenster et al., 2004; Strauss and Whittall, 2006).

Most studies have focused on the size-relationship between plant vegetative organs (Preston and Ackerly, 2003; Westoby and Wright, 2003; Sun et al., 2006; Yang et al., 2010; Fan et al., 2017). For example, various studies have shown that leaf and stem allometry are positively correlated (Preston and Ackerly, 2003; Westoby and Wright, 2003; Sun et al., 2006; Normand et al., 2008; Yang et al., 2010; Fan et al., 2017). These correlations imply that larger 
diameter branches can support large leaves mechanically and hydraulically (Niinemets et al., 2006; Normand et al., 2008).

Allometry is a useful integrative tool in zoology, indicating relationships between diverse measures, which has been widely used in plants (Western, 1979; Midgley and Bond, 1989). A previous study has shown that inflorescence size is allometrically related with leaf and stem size in Leucadendron and Protea (Proteaceae; Midgley and Bond, 1989). If these correlations are prevalent among flowering plants (Niklas and Enquist, 2003), reproductive organs may show similar correlations as those observed in vegetative organs. In other words, largediameter stems can support larger inflorescences. However, such allometric correlation has been rarely tested on reproductive organs.

The family Orchidaceae, one of the largest families of flowering plants, has diverse life forms, life histories, habitats, morphology, and physiology (Zhang et al., 2018). Furthermore, orchids are well known for their ornamental flowers, which have long floral lifespans (Zhang et al., 2018). Orchids bear inflorescences with one or more flowers (Chen et al., 2009), and show great diversity in floral number and size (De, 2020). In orchids, the flower peduncle plays an important role in mechanical support, water transport, and nutrient transfer. Previous research in orchids has mainly focused on the physiology of vegetative organs (Zhang et al., 2018) and pollination biology (Waterman and Bidartondo, 2008). However, little is known about the allometric correlation among reproductive organ sizes in the family.

In the present research, we assessed the correlations between the number and the size of inflorescences, flowers, and leaves of 26 orchid species with various life forms. We asked three specific questions: (1) are there differences in the number and area from flower and leaf between orchid species with different life forms; (2) do orchid species with larger leaf area have larger inflorescence traits; and (3) do orchid species with largediameter peduncles bear more and larger flowers concurrently than orchids with small peduncles? Our aims were to understand the development and allometry of reproductive and vegetative organs in Orchidaceae under natural selection.

\section{MATERIALS AND METHODS}

\section{Plant Materials}

We examined the traits of mature inflorescences, flowers, and leaves of 26 orchid species from 8 genera (Coelogyne, Cymbidium, Cypripedium, Dendrobium, Eria, Holcoglossum, Pholidota, and Paphiopedilum). Although all the studied species in this study are from the same family, Orchidaceae, their flower and leaf traits are different (Zhang et al., 2017). Here, 13 epiphytic orchids, 7 terrestrial orchids, and 6 facultative orchids of those studied orchid species were selected (Table 1). The inflorescences in these genera differ significantly (Figure 1) including erect, arching, or pendulous racemes from one flower up to many (up to 42) flowers. Inflorescences produced at the apical end of shoots are called terminal, the others arising from nodes near the base of pseudobulbs or leaf axils are lateral. The inflorescences of orchids are mostly terminal or lateral racemes (Arditti, 1992). Healthy, recently opened flowers and fully expanded leaves were collected from 3 to 6 individuals per

TABLE 1 | Ecological and phenological traits of the studied orchid species.

\begin{tabular}{|c|c|c|c|c|c|}
\hline Species & Life form & Number of flowers & Flowering period & Habitat & Altitude (m) \\
\hline Coelogyne nitida & Epiphytic & $2-3$ & March & On trees in the forest & $1,400-2,700$ \\
\hline Cymbidium aloifolium & Epiphytic & $15-35$ & April-May & On trees or rocks in the forest & $100-1,100$ \\
\hline Cymbidium bicolor & Epiphytic & $10-20$ & March-April & On trees in the forest & 1,600 \\
\hline Cymbidium dayanum & Epiphytic & 5-9 & August-December & On trees in the forest & $300-1,600$ \\
\hline Cymbidium erythraeum & Epiphytic & $3-7$ & October-January & On trees or rocks in the forest & $1,400-2,800$ \\
\hline Cymbidium faberi & Terrestrial & $5-11$ & March-May & Understory & 700-3,000 \\
\hline Cymbidium lancifolium & Facultative & $2-6$ & May-August & Understory or rocks & $300-2,200$ \\
\hline Cymbidium lowianum & Epiphytic & $10-20$ & April-May & On trees in the forest & $1,300-1900$ \\
\hline Cymbidium mastersii & Epiphytic & $2-5$ & October-December & On trees or rocks in the forest & $1,600-1800$ \\
\hline Cymbidium sinense & Terrestrial & 10-20 & October-March & Understory & 300-2000 \\
\hline Cymbidium tracyanum & Epiphytic & $>10$ & September-December & On trees in the forest & $1,200-1900$ \\
\hline Cypripedium subtropicum & Terrestrial & -7 & July & Understory & 1,400 \\
\hline Dendrobium chrysotoxum & Epiphytic & $>2$ & March-May & On trees or rocks in the forest & $520-1,620$ \\
\hline Eria coronaria & Epiphytic & $2-6$ & May-June & On trees or rocks in the forest & 1,300-2000 \\
\hline Holcoglossum kimballianum & Epiphytic & $>2$ & November & On trees in the forest & $1,000-1,630$ \\
\hline Pholidota chinensis & Epiphytic & $>20$ & April-May & On trees or rocks in the forest & 1,500 \\
\hline Paphiopedilum appletonianum & Terrestrial & 1 & January-May & Understory & $300-1,200$ \\
\hline Paphiopedilum armeniacum & Facultative & 1 & March-May & Rocky or in crevices of rocks & $1,400-2,250$ \\
\hline Paphiopedilum dianthum & Epiphytic & $2-4$ & September-November & On trees or rocks in the forest & $550-2,250$ \\
\hline Paphiopedilum gratrixianum & Terrestrial & 1 & September-December & Understory & $1800-1900$ \\
\hline Paphiopedilum henryanum & Facultative & 1 & September-November & On the grass slope of the edge of forest & $900-1,300$ \\
\hline Paphiopedilum hirsutissimum & Facultative & 1 & April-May & Understory & $300-1,500$ \\
\hline Paphiopedilum insigne & Terrestrial & 1 & October-December & On grassy and rocky slopes & $1,200-1,600$ \\
\hline Paphiopedilum malipoense & Terrestrial & 1 & January-April & Understory & $800-1,000$ \\
\hline Paphiopedilum purpuratum & Facultative & 1 & June-September & Understory or on rocks & $1,200-1,500$ \\
\hline Paphiopedilum tigrinum & Facultative & 1 & May-August & On trees or rocks in the forest & $1,200-2,200$ \\
\hline
\end{tabular}


species from the plants grown in a greenhouse at the Kunming Institute of Botany, Chinese Academy of Sciences $\left(25^{\circ} 01^{\prime} \mathrm{N}\right.$; $102^{\circ} 41^{\prime} \mathrm{E}$ ), under $30-40 \%$ full sunlight and temperatures of $20-25^{\circ} \mathrm{C}$.

\section{Measurements of Inflorescence and Flower and Leaf Area}

Whole flowering plants were selected, leaf number (LN) per flowering plant was recorded. The inflorescences and leaves of each collected species were excised in the morning, sealed in plastic bags, and immediately transported to our nearby laboratory. The inflorescence was selected to measure the lengths of inflorescence and to record the number of flowers (FN) when the top flower of the inflorescence was fully expanded. Inflorescence length (IL) was the length from the base of the inflorescence peduncle to the apex of the highest opened flower. Inflorescence length was measured using a ruler. The diameter of the peduncle (PD) was the average of two diameters which were measured along the major axis and the short axis with a vernier caliper. The newly opened flowers from the inflorescences were used to measure the floral area. Flowers (petals, sepals, and labellum) and leaves were cut into several sections, as they are uneven and tridimensional, to ensure they are flattened. The individual floral area was a total area corresponding to the sum of sepal, petal, and labellum. Individual floral area (IFA) and individual leaf area (ILA) were then determined with a Li-Cor 3000A area meter (Li-Cor, Inc., Lincoln, NE). Here, flower and leaf area were estimated: the total flower area (TFA) per inflorescence and total leaf area (TLA) per plant were estimated as the product of FN and
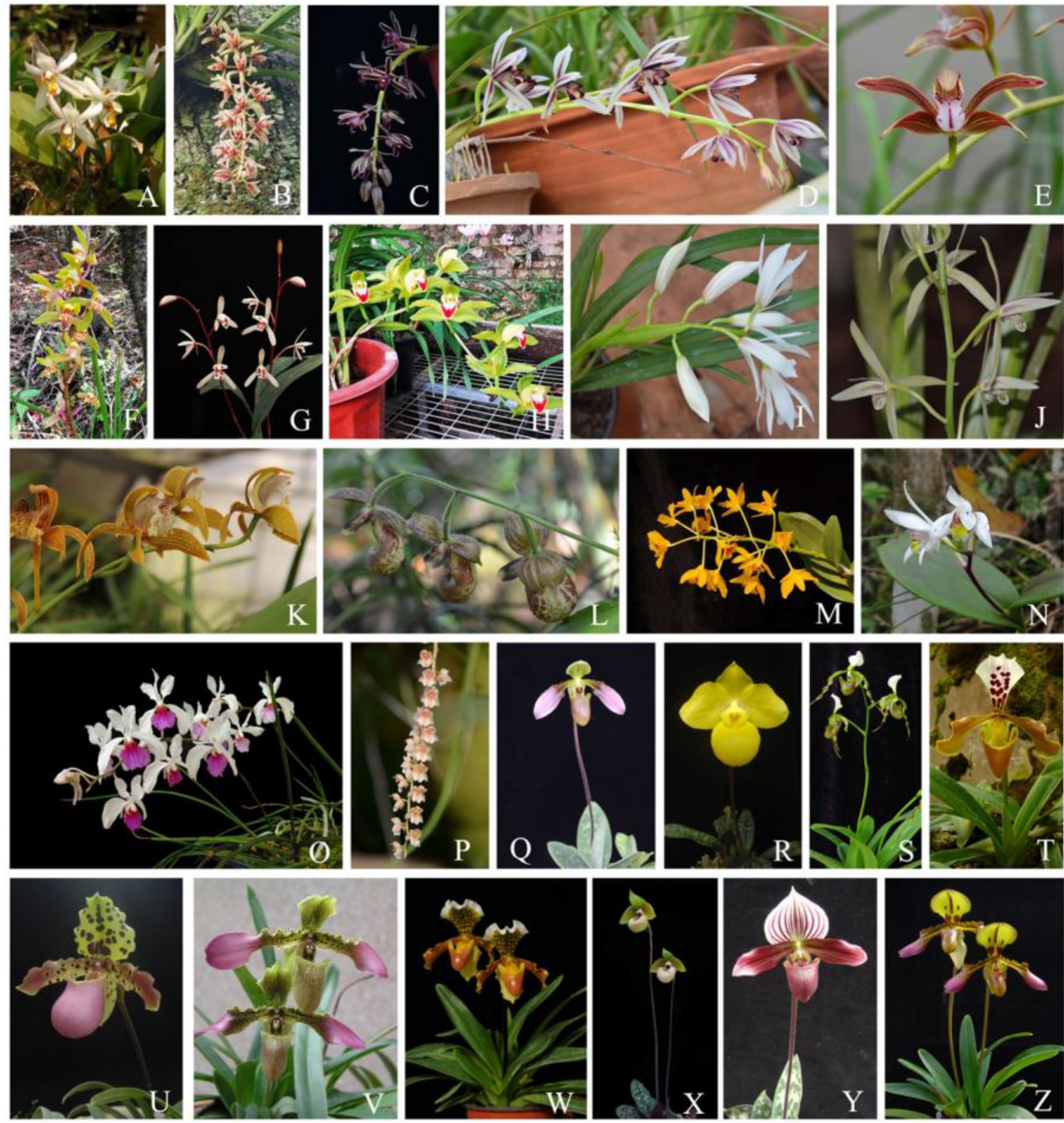

FIGURE 1 | Orchid species studied in the present study. (A) Coelogyne nitida; (B) Cymbidium aloifolium; (C) C. bicolor; (D) C. dayanum; (E) C. erythraeum; (F) C. faberi; (G) C. lancifolium; (H) C. lowianum; (I) C. mastersii; (J) C. sinense; (K) C. tracyanum; (L) Cypripedium subtropicum; (M) Dendrobium chrysotoxum; (N) Eria coronaria; (O) Holcoglossum kimballianum; (P) Pholidota chinensis; (Q) Paphiopedilum appletonianum; (R) P. armeniacum; (S) P. dianthum; (T) P. gratrixianum; (U) P. henryanum; (V) P. hirsutissimum; (W) P. insigne; (X) P. malipoense; (Y) P. purpuratum; (Z) P. tigrinum. Erect raceme (A,F,G,J,N,Q-Z); pendulous raceme (B-D,P); arching raceme (E,H,I,K-M,O). 
IFA, and LN and ILA, respectively. Subsequently, the inflorescences, flowers, and leaves were oven-dried at $70^{\circ} \mathrm{C}$ for $48 \mathrm{~h}$ to obtain their dry weights (DW). Flower dry mass per unit area (FMA, $\mathrm{g} \mathrm{m}^{-2}$ ) was calculated as FDW/IFA, and leaf dry mass per unit area (LMA, $\mathrm{g} \mathrm{m}^{-2}$ ) was calculated as LDW/ILA.

\section{Statistical Analysis}

Differences between leaf and flower traits were analyzed using Tukey's post hoc test after testing for normality and homogeneity of variances. All tests were made at a probability level of 5\%. All statistical analyses were performed using SPSS 16 (SPSS, Chicago, IL).

\section{RESULTS}

In order to reveal whether there are differences in leaf and flower traits of orchids with different life forms, 10 traits associated with inflorescences, flowers, and leaves were examined across the 26 orchid species sampled (Tables 2 and 3). Statistical analysis showed that flower number and area differed significantly between orchid life forms (Figure 2). Epiphytic species had more flowers per inflorescence $(12.56 \pm 3.17)$ than terrestrial species $(3.87 \pm 1.66$; $p=0.04)$. Furthermore, the flowers of epiphytic species had smaller area $\left(20.09 \pm 4.84 \mathrm{~cm}^{2}\right)$ than those of terrestrial species $\left(44.63 \pm 10.26 \mathrm{~cm}^{2} ; p=0.02\right)$. Facultative species had significantly fewer flowers $(1.72 \pm 0.72)$ than did epiphytic species $(p=0.02)$, but flower number did not significantly differ between facultative and terrestrial species $(p=0.66)$. Flower area was significantly larger in facultative species $\left(48.10 \pm 9.53 \mathrm{~cm}^{2}\right)$ than in epiphytic species $(p=0.02)$, but it was not significantly different between facultative species and terrestrial species $(p=0.78)$.

To further reveal the correlation between leaf traits and inflorescence traits, we found they were significantly correlated among them (Figure 3). For example, individual leaf area was positively correlated with peduncle diameter, inflorescence length, total floral area, and floral dry mass per unit area. Similarly, total leaf area was positively correlated with peduncle diameter, inflorescence length, total floral area, and floral dry mass per unit area.
The correlation among peduncle diameter, inflorescence length, flower number, individual floral area, total floral area, and floral dry mass per unit area was also analyzed in inflorescences (Figure 3). Peduncle diameter was positively correlated with inflorescence length, total floral area, and floral dry mass per unit area. However, flower number was negatively correlated with individual floral area. In addition, inflorescence length was positively correlated with total floral area and floral dry mass per unit area, while not correlated with individual floral area and flower number.

\section{DISCUSSION}

Different leaf and flower traits of various life forms are adapted to special habitats. Compared with terrestrial habitats, epiphytic habitats are stressed by water and nutrients (Benzing, 1990). Therefore, epiphytic species have higher velamen thickness, stomatal density, and leaf vein density than terrestrial species to add nutrients' absorption and to reduce water loss (Zhang et al., 2012; Zotz and Winkler, 2013). However, the comparative study on flower traits between terrestrial and epiphytic orchid species is still lacking. In our study, we found that epiphytic species have lower flower area, while having a higher flower number than those of terrestrial species. We speculate that these differences may not only correlate to the water status of the flower but also correlate to the pollinator activities (Roddy and Dawson, 2012; Teixido and Valladares, 2014).

Leaf size and inflorescence size may be correlated in various plant species (Midgley and Bond, 1989). We also found that leaf area was positively correlated with peduncle diameter and inflorescence length. The larger leaf area can apply enough resources to construct the thicker peduncle diameter, larger inflorescence length, and flower area (Pleasants and Zimmerman, 1990). This correlation also indicated that there is a significant trade-off between leaf area and flower traits. To some extent, the allometry correlation between leaf area and flower traits contributed to the developmental or genetic constraints (Ackerly and Donoghue, 1998; Lambrecht and Dawson, 2007; Steven et al., 2019).

TABLE 2 | Measured traits and units for inflorescences, flowers, and leaves from the studied orchid species.

\begin{tabular}{|c|c|c|c|c|c|c|}
\hline Traits & Abbreviation & Unit & Mean \pm SE & Min & Max & CV (\%) \\
\hline Leaf number & LN & No. & $5.53 \pm 0.52$ & 2.00 & 11.33 & 48.43 \\
\hline Individual leaf area & ILA & $\mathrm{cm}^{2}$ & $64.67 \pm 10.17$ & 14.63 & 226.30 & 80.17 \\
\hline Total leaf area & TLA & $\mathrm{cm}^{2}$ & $420.60 \pm 88.68$ & 57.75 & 1764.89 & 107.52 \\
\hline $\begin{array}{l}\text { Leaf dry mass per unit } \\
\text { area }\end{array}$ & LMA & $\mathrm{gm}^{-2}$ & $130.44 \pm 9.68$ & 42.47 & 294.87 & 37.86 \\
\hline Peduncle diameter & PD & $\mathrm{mm}^{2}$ & $3.63 \pm 0.39$ & 1.39 & 10.70 & 55.48 \\
\hline Inflorescence length & IL & $\mathrm{cm}$ & $39.57 \pm 4.53$ & 10.18 & 90.20 & 58.40 \\
\hline Flower number & $\mathrm{FN}$ & No. & $7.96 \pm 1.89$ & 1.00 & 41.83 & 120.89 \\
\hline Individual floral area & IFA & $\mathrm{cm}^{2}$ & $34.81 \pm 4.93$ & 0.90 & 84.81 & 70.20 \\
\hline Total floral area & TFA & $\mathrm{cm}^{2}$ & $146.45 \pm 32.54$ & 32.50 & 678.15 & 113.29 \\
\hline $\begin{array}{l}\text { Floral dry mass per } \\
\text { unit area }\end{array}$ & FMA & $\mathrm{gm}^{-2}$ & $39.04 \pm 2.56$ & 15.33 & 70.49 & 33.37 \\
\hline
\end{tabular}

$C V$, coefficient of variation. 
TABLE 3 | The leaf and floral traits in the 26 orchid species studied.

\begin{tabular}{|c|c|c|c|c|c|c|c|c|c|c|c|}
\hline Species & $\mathbf{N}$ & LN & ILA & TLA & LMA & PD & IL & FN & IFA & TFA & FMA \\
\hline Coelogyne nitida & 3 & $2.00 \pm 0.00$ & $37.21 \pm 2.35$ & $74.43 \pm 4.70$ & $107.28 \pm 5.59$ & $1.39 \pm 0.10$ & $21.22 \pm 2.12$ & $4.33 \pm 0.67$ & $16.95 \pm 0.16$ & $73.25 \pm 10.80$ & $41.24 \pm 3.77$ \\
\hline Cymbidium aloifolium & 6 & $4.17 \pm 0.17$ & $93.26 \pm 7.24$ & $393.66 \pm 47.61$ & $253.11 \pm 7.98$ & $5.66 \pm 0.18$ & $58.45 \pm 3.32$ & $31.17 \pm 1.40$ & $5.78 \pm 0.31$ & $180.45 \pm 13.19$ & $49.01 \pm 1.64$ \\
\hline Cymbidium bicolor & 6 & $6.33 \pm 0.33$ & $57.67 \pm 3.09$ & $366.40 \pm 31.09$ & $294.87 \pm 15.42$ & $3.63 \pm 0.07$ & $21.28 \pm 1.10$ & $12.83 \pm 0.91$ & $5.07 \pm 0.09$ & $65.11 \pm 4.82$ & $49.40 \pm 1.46$ \\
\hline Cymbidium dayanum & 3 & $8.33 \pm 0.33$ & $87.37 \pm 0.22$ & $728.26 \pm 31.06$ & $114.96 \pm 1.54$ & $2.96 \pm 0.22$ & $21.17 \pm 2.97$ & $7.00 \pm 1.53$ & $7.94 \pm 0.07$ & $55.39 \pm 11.64$ & $36.29 \pm 4.21$ \\
\hline Cymbidium erythraeum & 5 & $9.60 \pm 0.51$ & $47.79 \pm 11.61$ & $478.73 \pm 140.19$ & $90.11 \pm 1.90$ & $3.38 \pm 0.30$ & $67.46 \pm 7.12$ & $8.20 \pm 1.16$ & $13.39 \pm 0.81$ & $110.79 \pm 17.51$ & $47.71 \pm 3.36$ \\
\hline Cymbidium faberi & 5 & $10.00 \pm 0.00$ & $92.27 \pm 5.78$ & $922.67 \pm 57.82$ & $124.48 \pm 5.68$ & $7.52 \pm 0.12$ & $45.61 \pm 0.50$ & $10.00 \pm 0.58$ & $39.82 \pm 1.60$ & $396.72 \pm 14.11$ & $44.19 \pm 2.59$ \\
\hline Cymbidium lancifolium & 6 & $2.50 \pm 0.22$ & $37.58 \pm 2.67$ & $94.40 \pm 12.05$ & $98.66 \pm 4.73$ & $2.46 \pm 0.08$ & $20.97 \pm 1.90$ & $5.33 \pm 0.42$ & $6.08 \pm 0.33$ & $32.50 \pm 3.13$ & $28.63 \pm 0.59$ \\
\hline Cymbidium lowianum & 4 & $6.50 \pm 1.04$ & $175.23 \pm 29.33$ & $1212.89 \pm 357.96$ & $125.65 \pm 6.78$ & $6.25 \pm 0.28$ & $85.43 \pm 5.98$ & $13.00 \pm 1.29$ & $43.84 \pm 0.42$ & $570.91 \pm 60.32$ & $70.49 \pm 4.51$ \\
\hline Cymbidium mastersii & 3 & $11.33 \pm 1.20$ & $75.58 \pm 4.18$ & $866.62 \pm 134.83$ & $117.43 \pm 4.62$ & $4.25 \pm 0.27$ & $27.23 \pm 3.69$ & $5.00 \pm 1.15$ & $24.42 \pm 0.65$ & $122.18 \pm 27.78$ & $31.30 \pm 1.32$ \\
\hline Cymbidium sinense & 5 & $6.00 \pm 0.32$ & $118.50 \pm 8.98$ & $705.89 \pm 49.03$ & $126.18 \pm 5.76$ & $4.06 \pm 0.35$ & $52.76 \pm 4.52$ & $12.60 \pm 0.93$ & $10.26 \pm 0.83$ & $130.73 \pm 16.78$ & $33.71 \pm 1.57$ \\
\hline Cymbidium tracyanum & 3 & $8.00 \pm 1.00$ & $226.30 \pm 25.36$ & $1764.89 \pm 81.24$ & $112.92 \pm 7.17$ & $10.70 \pm 0.55$ & $90.20 \pm 5.46$ & $13.67 \pm 0.33$ & $49.65 \pm 2.49$ & $678.15 \pm 34.80$ & $60.44 \pm 4.38$ \\
\hline $\begin{array}{l}\text { Cypripedium } \\
\text { subtropicum }\end{array}$ & 6 & $9.20 \pm 0.20$ & $133.17 \pm 2.38$ & $1223.60 \pm 14.62$ & $42.47 \pm 1.84$ & $4.24 \pm 0.42$ & $28.48 \pm 4.35$ & $6.60 \pm 1.36$ & $47.55 \pm 2.92$ & $322.83 \pm 74.10$ & $23.46 \pm 1.34$ \\
\hline $\begin{array}{l}\text { Dendrobium } \\
\text { chrysotoxum }\end{array}$ & 6 & $3.17 \pm 0.17$ & $24.14 \pm 3.65$ & $75.98 \pm 10.96$ & $117.83 \pm 4.37$ & $3.12 \pm 0.12$ & $16.71 \pm 1.23$ & $11.33 \pm 0.67$ & $16.74 \pm 0.88$ & $190.90 \pm 16.43$ & $41.17 \pm 1.00$ \\
\hline Eria coronaria & 5 & $2.20 \pm 0.20$ & $52.89 \pm 2.52$ & $115.22 \pm 7.84$ & $142.09 \pm 2.52$ & $2.33 \pm 0.09$ & $10.18 \pm 0.56$ & $4.40 \pm 0.40$ & $9.09 \pm 0.25$ & $39.96 \pm 3.59$ & $30.27 \pm 0.37$ \\
\hline $\begin{array}{l}\text { Holcoglossum } \\
\text { kimballianum }\end{array}$ & 5 & $6.60 \pm 0.40$ & $14.63 \pm 1.04$ & $97.58 \pm 11.89$ & $152.00 \pm 8.14$ & $1.99 \pm 0.15$ & $34.04 \pm 5.58$ & $8.00 \pm 1.14$ & $15.11 \pm 0.92$ & $124.28 \pm 22.90$ & $15.33 \pm 0.95$ \\
\hline Pholidota chinensis & 6 & $2.00 \pm 0.00$ & $33.12 \pm 2.08$ & $66.23 \pm 4.15$ & $103.08 \pm 7.32$ & $2.05 \pm 0.10$ & $24.00 \pm 0.88$ & $41.83 \pm 1.30$ & $0.90 \pm 0.03$ & $37.41 \pm 1.09$ & $18.33 \pm 1.51$ \\
\hline $\begin{array}{l}\text { Paphiopedilum } \\
\text { appletonianum }\end{array}$ & 6 & $3.83 \pm 0.17$ & $23.09 \pm 5.14$ & $89.16 \pm 21.27$ & $123.82 \pm 10.16$ & $2.25 \pm 0.10$ & $47.70 \pm 3.31$ & $1.00 \pm 0.00$ & $39.16 \pm 2.46$ & $39.16 \pm 2.46$ & $40.03 \pm 1.86$ \\
\hline $\begin{array}{l}\text { Paphiopedilum } \\
\text { armeniacum }\end{array}$ & 6 & $3.67 \pm 0.20$ & $19.65 \pm 1.55$ & $71.45 \pm 5.86$ & $113.08 \pm 3.47$ & $2.44 \pm 0.10$ & $48.60 \pm 3.80$ & $1.00 \pm 0.00$ & $74.64 \pm 4.09$ & $74.64 \pm 4.09$ & $20.74 \pm 0.66$ \\
\hline $\begin{array}{l}\text { Paphiopedilum } \\
\text { dianthum }\end{array}$ & 5 & $4.40 \pm 0.51$ & $91.17 \pm 5.75$ & $397.09 \pm 42.66$ & $178.80 \pm 8.64$ & $4.28 \pm 0.14$ & $38.62 \pm 2.49$ & $2.60 \pm 0.24$ & $52.24 \pm 1.57$ & $135.98 \pm 13.80$ & $53.94 \pm 1.90$ \\
\hline $\begin{array}{l}\text { Paphiopedilum } \\
\text { gratrixianum }\end{array}$ & 5 & $4.00 \pm 0.00$ & $27.90 \pm 3.51$ & $111.62 \pm 14.05$ & $144.31 \pm 14.11$ & $2.50 \pm 0.11$ & $22.60 \pm 1.71$ & $1.00 \pm 0.00$ & $57.45 \pm 4.72$ & $57.45 \pm 4.72$ & $34.76 \pm 2.74$ \\
\hline $\begin{array}{l}\text { Paphiopedilum } \\
\text { henryanum }\end{array}$ & 5 & $3.40 \pm 0.24$ & $17.35 \pm 3.27$ & $57.75 \pm 9.19$ & $133.12 \pm 6.04$ & $2.30 \pm 0.11$ & $19.76 \pm 1.56$ & $1.00 \pm 0.00$ & $48.81 \pm 1.75$ & $48.81 \pm 1.75$ & $29.45 \pm 1.61$ \\
\hline $\begin{array}{l}\text { Paphiopedilum } \\
\text { hirsutissimum }\end{array}$ & 6 & $6.83 \pm 0.54$ & $43.42 \pm 8.30$ & $283.88 \pm 47.62$ & $139.72 \pm 3.45$ & $3.37 \pm 0.25$ & $35.10 \pm 1.80$ & $1.00 \pm 0.00$ & $52.97 \pm 3.10$ & $52.97 \pm 3.10$ & $54.43 \pm 2.34$ \\
\hline Paphiopedilum insigne & 5 & $3.60 \pm 0.24$ & $49.01 \pm 4.03$ & $178.74 \pm 23.82$ & $117.83 \pm 8.92$ & $3.22 \pm 0.08$ & $26.60 \pm 2.36$ & $1.00 \pm 0.00$ & $76.18 \pm 4.96$ & $76.18 \pm 4.96$ & $42.37 \pm 1.70$ \\
\hline $\begin{array}{l}\text { Paphiopedilum } \\
\text { malipoense }\end{array}$ & 6 & $6.67 \pm 0.21$ & $48.80 \pm 1.25$ & $324.38 \pm 7.49$ & $125.90 \pm 8.23$ & $2.65 \pm 0.15$ & $94.01 \pm 4.14$ & $1.00 \pm 0.00$ & $84.81 \pm 3.81$ & $84.81 \pm 3.81$ & $36.32 \pm 1.23$ \\
\hline $\begin{array}{l}\text { Paphiopedilum } \\
\text { purpuratum }\end{array}$ & 5 & $6.00 \pm 0.32$ & $19.35 \pm 1.95$ & $116.50 \pm 13.46$ & $88.16 \pm 3.38$ & $2.27 \pm 0.06$ & $31.28 \pm 0.95$ & $1.00 \pm 0.00$ & $43.48 \pm 2.22$ & $43.48 \pm 2.22$ & $36.97 \pm 1.47$ \\
\hline Paphiopedilum tigrinum & 5 & $3.40 \pm 0.24$ & $34.92 \pm 2.13$ & $117.62 \pm 7.30$ & $103.53 \pm 2.39$ & $3.03 \pm 0.04$ & $39.44 \pm 1.90$ & $1.00 \pm 0.00$ & $62.63 \pm 4.33$ & $62.63 \pm 4.33$ & $45.14 \pm 1.44$ \\
\hline
\end{tabular}

N, sample number: LN, leaf number; ILA, individual leaf area; TLA, total leaf area; LMA, leaf dry mass per unit area; PD, peduncle diameter; IL, inflorescence length; FN, flower number; IFA, individual floral area; TFA, total floral area; FMA, floral dry mass per unit area. Each value is mean $\pm S E$. 

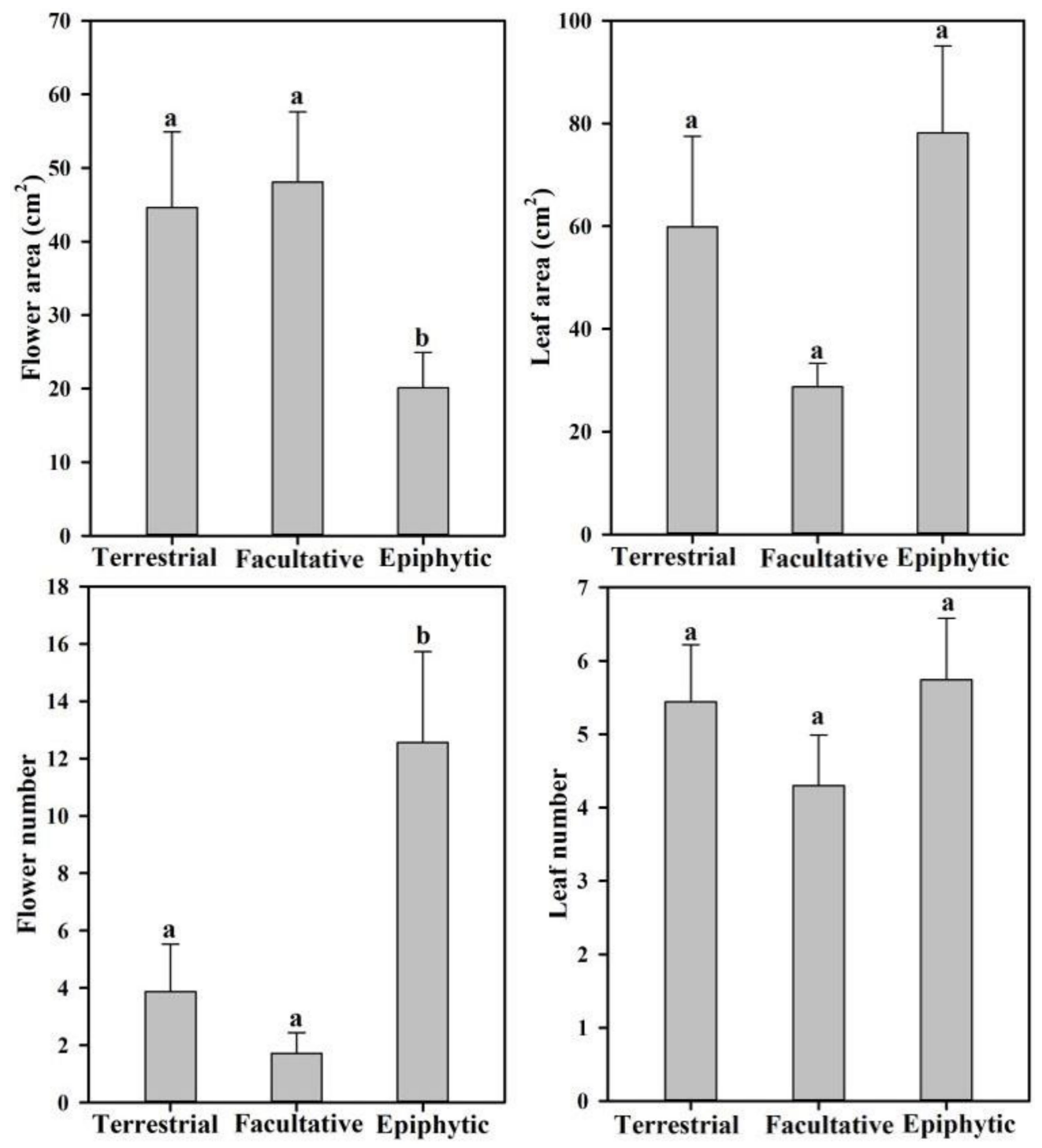

FIGURE 2 | Differences in the number and area of flower and leaf from 26 terrestrial, facultative, and epiphytic orchid species.

We found that inflorescence length was correlated with peduncle diameter and total floral area (Figure 3), but not with individual floral area or flower number. This correlation can also be found between peduncle diameter and total floral area or floral dry mass per unit area, which implies more biomass investment to the peduncle with the increase of total floral area as the correlation between petiole lamina size and size (Fan et al., 2017). Our findings coincide with the allometric correlations in other taxa. For example, a previous work on Leucadendron (Proteaceae) showed that inflorescence length is positively correlated with stem thickness (Midgley and Bond, 1989). Inflorescence architecture is closely related to the arrangement of each flower on an inflorescence (Prusinkiewicz et al., 2007). However, thus far, the study on the correlation between peduncle diameter and inflorescence architecture is still lacking. In our study, we found no significant correlation between peduncle diameter and inflorescence architecture. For example, compared with
C. lancifolium, which has a thinner peduncle but erect racemes, C. aloifolium has a thicker peduncle but pendulous racemes. These results indicate that the inflorescence architecture may be related to the specific habitat (Schoen and Dubuc, 1990). Taken together, these findings imply that inflorescences provide water, nutrients, and mechanical support to flowers, which is analogous to what twigs (stems) provide to leaves (Niklas and Enquist, 2003; Fan et al., 2017). Likewise, the allometric relationship between leaf area (mass) and petiole area (mass) was found, indicating that larger leaves invest a higher fraction of biomass in the petiole than smaller leaves (Fan et al., 2017). Our finding was also important in horticultural applications. Previous studies have shown that crosses between orchids with different numbers of flowers, but similar peduncle diameters, can produce hybrids with intermediate flower numbers such as Orchis pauciflora and $O$. mascula (Cozzolino et al., 2006) or Anacamptis $\times$ albuferensis (Bateman and Hollingsworth, 2004). In contrast, crosses between 


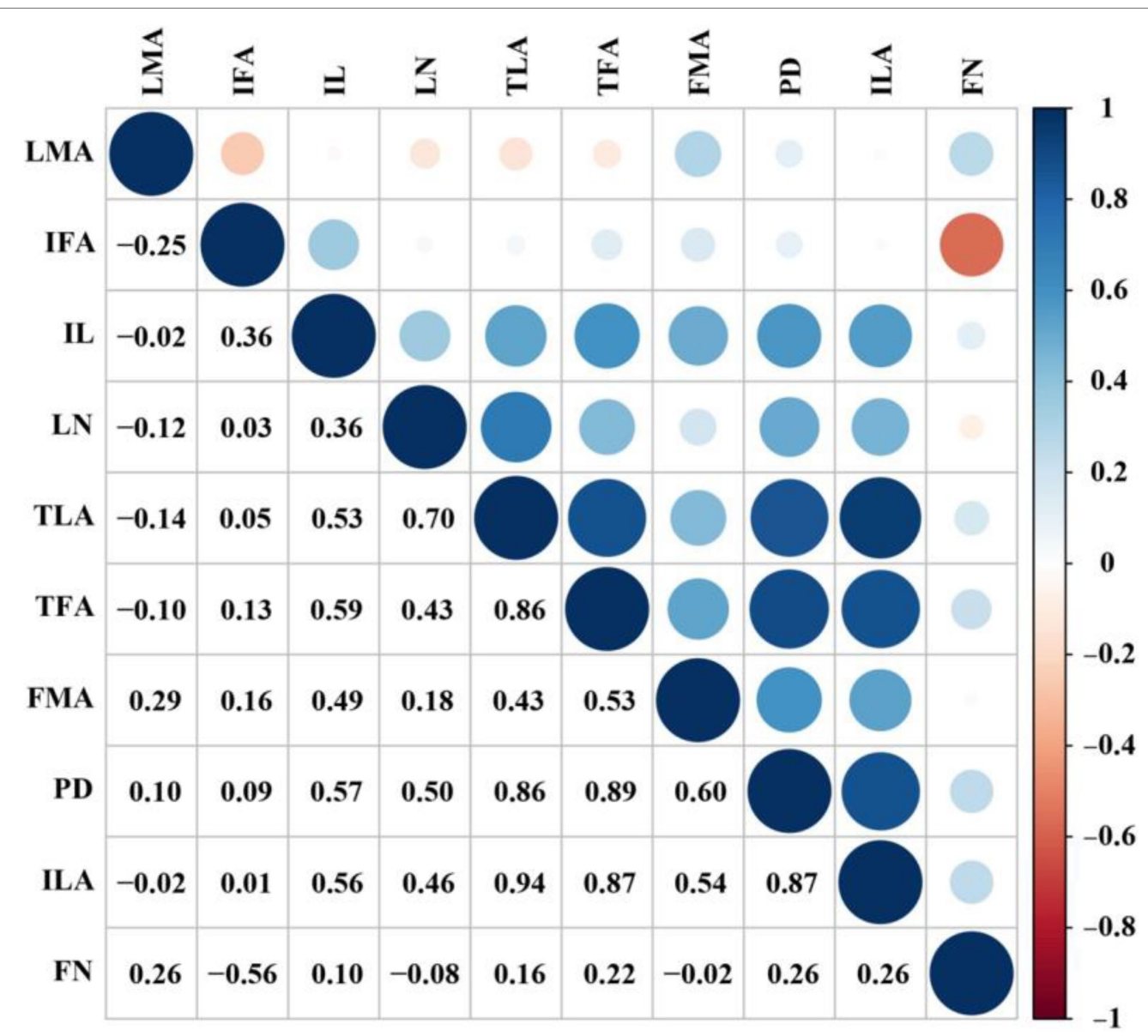

FIGURE 3 | Correlations among inflorescence, floral, and leaf traits of the 26 orchids studied. Circle sizes represent the significance (upper right of the diagonal) and correlation coefficient (lower right of the diagonal). LN, leaf number; ILA, individual leaf area; TLA, total leaf area; LMA, leaf dry mass per unit area; PD, peduncle diameter; IL, inflorescence length; FN, flower number; IFA, individual floral area; TFA, total floral area; FMA, floral dry mass per unit area.

orchids with similar flower numbers but different peduncle diameters produce offspring with thicker peduncle diameters and more flowers than their parentals (Yan et al., 2017).

The absence of significant correlations between flower number or flower area with leaf number or leaf area strongly suggests that orchid flower and leaf traits are two functional traits independent of evolution (Zhang et al., 2017), which might result from not only biotic and abiotic pressures but also the functions of different organs. This differentiation is consistent with the prevalence of differing selective pressures upon fundamental function and genetic background of reproductive vs. vegetative organs (Juenger et al., 2005; Pélabon et al., 2011; Roddy et al., 2013). For example, leaf number reduces significantly under water stress (Descamps et al., 2020). Leaf area tends to be small in poor habitats (Yang et al., 2010). Different from leaves, in order to ensure successful reproduction, plants can regulate the flower number in specific environments (Prusinkiewicz et al., 2007). The flower number and area are significantly decreased with the increase of temperatures (Descamps et al., 2020). The positive correlation observed here between total floral area and total leaf area indicated the importance of the coordinating role of the size between reproductive and vegetative organs. Larger leaf area may assimilate more carbon, thus more carbon can be used in flowers (Lambrecht and Dawson, 2007). A previous study has suggested that larger flowers produce a better return for plant reproductive success and fitness than smaller flowers (Sargent et al., 2007). Larger flowers can receive more pollinators, and it seems probable that larger flowers enhance reproductive fitness in the plant-pollinator system (Galen, 1989; Teixido and Valladares, 2014). Studies on Paphiopedilum and Cymbidium species indicate that plants with larger and more flowers have more fruit sets (Bänziger, 1996; Cheng et al., 2007; Shi et al., 2007; Yu et al., 2008). For example, P. dianthum, which has twice the floral area of $P$. villosum and nearly three times the number of flowers, sets roughly eight times the amount of fruit (Bänziger, 1996). However, larger flowers may also increase construction and maintenance costs. Hence, future work should focus on addressing how plants trade-off between the size of flowers and physiological maintenance costs.

\section{CONCLUSION}

Our study demonstrated that inflorescence length in orchids is correlated with peduncle diameter, total floral area, and 
individual and total leaf area. However, inflorescence length is not correlated with individual floral area or flower number. These results provide novel insights into the development and allometry of reproductive and vegetative organs in Orchidaceae under natural selection. Moreover, our findings are of broader significance to breeding new hybrid orchids.

\section{DATA AVAILABILITY STATEMENT}

The original contributions presented in the study are included in the article/supplementary material, further inquiries can be directed to the corresponding authors.

\section{AUTHOR CONTRIBUTIONS}

F-PZ, S-BZ, J-QF, and $\mathrm{HH}$ designed the study and conceived the manuscript. J-QF collected the samples and data. F-PZ conducted statistical analyses and wrote the first draft of the manuscript. All authors contributed to the article and approved the submitted version.

\section{REFERENCES}

Ackerly, D. D., and Donoghue, M. J. (1998). Leaf size, sapling allometry, and Corner's rules: phylogeny and correlated evolution in maples (Acer). Am. Nat. 152, 769-791. doi: 10.1086/286208

Arditti, J. (1992). Fundamentals of Orchid Biology. Ithaca and London: Cornell University Press.

Armbruster, W. S. (1996). "Evolution of floral morphology and function: an integrated approach to adaptation, constraint, and compromise in Dalechampia (Euphorbiaceae)," in Floral Biology. eds. D. G. Lloyd and S. C. H. Barrett (New York: Chapman \& Hall), 241-272.

Bänziger, H. (1996). The mesmerizing wart: the pollination strategy of epiphytic lady slipper orchid Paphiopedilum villosum (Lindl.) stein (Orchidaceae). Bot. J. Linn. Soc. 121, 59-90. doi: 10.1111/j.1095-8339.1996.tb00745.x

Bateman, R. M., and Hollingsworth, P. M. (2004). Morphological and molecular investigation of the parentage and maternity of Anacamptis $\times$ albuferensis (A. fragrans $\times$ A. robusta), a new bybrid orchid from Mallorca, Spain. Taxon 53, 43-54. doi: 10.2307/4135487

Benzing, D. H. (1990). Vascular Epiphytes. General Biology and Related Biota. Cambridge: Cambridge University Press.

Chen, X. Q., Liu, Z. J., Zhu, G. H., Lang, K. Y., Ji, Z. H., Luo, Y. B., et al. (2009). "Orchidaceae," in Flora of China. Vol. 25. eds. Z. Y. Wu, P. H. Raven and D. Y. Hong (Beijing/St. Louis: Science Press/Missouri Botanical Garden Press).

Cheng, J., Liu, S. Y., He, R., Wei, X. L., and Luo, Y. B. (2007). Food-deceptive pollination in Cymbidium lancifolium (Orchidaceae) in Guangxi, China. Biodivers. Sci. 15, 608-617. doi: 10.1360/biodiv.070091

Cozzolino, S., Nardella, A. M., Impagliazzo, S., Widmer, A., and Lexer, C. (2006). Hybridization and conservation of Mediterranean orchids: should we product the orchid hybrids or the orchid hybrid zones? Biol. Conserv. 129, 14-23. doi: 10.1016/j.biocon.2005.09.043

Darwin, C. (1859). On the Origin of Species by Means of Natural Selection. London: John Murray.

De, L. C. (2020). Morphological diversity in orchids. Int. J. Bot. Stud. 5, 229-238. doi: $10.13140 /$ RG.2.2.24041.31849

Descamps, D., Marée, S., Hugon, S., Quinet, M., and Jacquemart, A. L. (2020). Species-specific responses to combined water stress and increasing temperatures in two be-pollinated congeners (Echium, Boraginaceae). Ecol. Evol. 10, 6549-6561. doi: 10.1002/ece3.6389

\section{FUNDING}

This study was supported by the National Natural Science Foundation of China (31970361 and 31960224), the "Young Top Talents" of the Ten Thousand Talents Plan in Yunnan Province (YNWR-QNBJ-2018-337), Science Research of Yunnan Provincial Department of Education (2019J1068), Yunnan Applied Basic Research Project (2018FA016), the Project for Construction of International Flower Technology Innovation Center and Achievement Industrialization (2019ZG006), Yunnan Provincial Science and Technology Department-Applied Basic Research Joint Special Funds of Yunnan University of Chinese Medicine (202001AZ070001-041), the Project for Innovation Team of Yunnan Province (202105AE160012), and the Digital Development and Application of Biological Resources in Yunnan Province (202002AA100007).

\section{ACKNOWLEDGMENTS}

We thank Wei Zhang and Xue-Wei Fu for providing beautiful orchid pictures.

Elle, E. (2004). "Floral adaptation and biotic and abiotic selection pressures," in Plant Adaptation: Molecular Genetics and Ecology. eds. Q. C. B. Cronk, J. Whitton, R. H. Ree and I. E. P. Taylor (Ottawa: NRC Research), 111-118.

Fan, Z. X., Sterck, F., Zhang, S. B., Fu, P. L., and Hao, G. Y. (2017). Trade-off between stem hydraulic efficiency and mechanical strength affects leaf-stem allometry in 28 Ficus tree species. Front. Plant Sci. 8:1619. doi: 10.3389/ fpls.2017.01619

Fenster, C. B., Armbruster, W. S., Wilson, P., Dudash, M. R., and Thomson, J. D. (2004). Pollination syndromes and floral specialization. Annu. Rev. Ecol. Evol. Syst. 35, 375-403. doi: 10.1146/annurev.ecolsys.34.011802.132347

Galen, C. (1989). Measuring pollinator-mediated selection on morphometric floral traits: bumblebees and the alpine sky pilot, Polemonium viscosum. Evolution 43, 882-890. doi: 10.1111/j.1558-5646.1989.tb05185.x

Galen, C., Sherry, R. A., and Carroll, A. B. (1999). Are flowers physiological sinks or faucets? Costs and correlates of water use by flowers of Polemonium viscosum. Oecologia 118, 461-470. doi: 10.1007/s004420050749

Grant, V. (1950). The protection of the ovules in flowering plants. Evolution 4, 179-201. doi: 10.1111/j.1558-5646.1950.tb01392.x

Harder, L. D., and Johnson, S. D. (2005). Adaptive plasticity of floral display size in animal-pollinated plants. Proc. Royal Soc. B Biol. Sci. 272, 2651-2657. doi: $10.1098 / \mathrm{rspb} .2005 .3268$

Iwata, T., Nagasaki, O., Ishii, H. S., and Ushimaru, A. (2012). Inflorescence architecture affects pollinator behaviour and mating success in Spiranthes sinensis (Orchidaceae). New Phytol. 193, 196-203. doi: 10.1111/j.1469-8137.2011.03892.x

Juenger, T., Pérez-Pérez, J. M., Bernal, S., and Micol, J. L. (2005). Quantitative trait loci mapping of floral and leaf morphology traits in Arabidopsis thaliana: evidence for modular genetic architecture. Evol. Dev. 7, 259-271. doi: 10.1111/j. 1525-142X.2005.05028.x

Lambrecht, S. C., and Dawson, T. E. (2007). Correlated variation of floral and leaf traits along a moisture availability gradient. Oecologia 151, 574-583. doi: $10.1007 / \mathrm{s} 00442-006-0617-7$

Midgley, J., and Bond, W. (1989). Leaf size and inflorescence size may be allometrically related traits. Oecologia 78, 427-429. doi: 10.1007/ BF00379120

Niinemets, Ü., Portsmuch, A., and Tobias, M. (2006). Leaf size modifies support biomass distribution among stems, petioles and mid-ribs in temperate plants. New Phytol. 171, 91-104. doi: 10.1111/j.1469-8137.2006.01741.x

Niklas, K. J., and Enquist, B. J. (2003). An allometric model for seed plant reproduction. Evol. Ecol. Res. 5, 79-88. 
Normand, F., Bissery, C., Damour, G., and Lauri, P. E. (2008). Hydraulic and mechanical stem properties affect leaf-stem allometry in mango cultivars. New Phytol. 178, 590-602. doi: 10.1111/j.1469-8137.2008.02380.x

Pélabon, C., Armbruster, W. S., and Hansen, T. F. (2011). Experimental evidence for the Berg hypothesis: vegetative traits are more sensitive than pollination traits to environmental variation. Funct. Ecol. 25, 247-257. doi: 10.1111/j.1365-2435.2010.01770.x

Pleasants, J., and Zimmerman, M. (1990). The effect of inflorescence size on pollinator visitation of Delphinium nelsonii and Aconitum columbianum. Collect. Bot. 19, 21-39. doi: 10.3989/collectbot.1990.v19.115

Preston, K. A., and Ackerly, D. D. (2003). Hydraulic architecture and the evolution of shoot allometry in contrasting climates. Am. J. Bot. 90, 1502-1512. doi: 10.3732/ajb.90.10.1502

Prusinkiewicz, P., Erasmus, Y., Lane, B., Harder, L. D., and Coen, E. (2007). Evolution and development of inflorescence architectures. Science 316, 1452-1456. doi: 10.1126/science.1140429

Roddy, A. B., and Dawson, T. E. (2012). Determining the water dynamics of flowering using miniature sap flow sensors. Acta Hortic. 951, 47-53. doi: 10.17660/actahortic.2012.951.4

Roddy, A. B., Guilliams, C. M., Lilittham, T., Farmer, J., Wormser, V., Pham, T., et al. (2013). Uncorrelated evolution of leaf and petal venation patterns across the angiosperm phylogeny. J. Exp. Bot. 64, 4081-4088. doi: 10.1093/jxb/ert247

Sargent, R. D., Goodwillie, C., Kalisz, S., and Ree, R. H. (2007). Phylogenetic evidence for a flower size and number trade-off. Am. J. Bot. 94, 2059-2062. doi: 10.3732 ajb.94.12.2059

Schoen, D. J., and Dubuc, M. (1990). The evolution of inflorescence size and number: a gamete-packaging in plants. Am. Nat. 135, 841-857. doi: 10.1086/285077

Shi, J., Cheng, J., Luo, D., Shangguan, F. Z., and Luo, Y. B. (2007). Pollination syndromes predict brood-site deceptive pollination by female hoverflies in Paphiopedilum dianthum (Orchidaceae). Acta Phytotax. Sin. 45, 551-560. doi: 10.1360/aps07025

Steven, J. C., Anderson, I. A., Brodie, E. D., and Delph, L. F. (2019). Rapid reversal of a potentially constraining genetic covariance between leaf and flower traits in Silene latifolia. Ecol. Evol. 10, 569-578. doi: 10.1002/ece3.5932

Strauss, S. Y., and Whittall, J. B. (2006). "Non-pollinator agents of selection on floral traits," in Ecology and Evolution of Flowers. eds. D. G. Lloyd and S. C. H. Barrett (Oxford: Oxford University Press), 120-138.

Sun, S. C., Jin, D. M., and Shi, P. L. (2006). The leaf size - twig size spectrum of temperate woody species along an altitudinal gradient: an invariant allometric scaling relationship. Ann. Bot. 97, 97-107. doi: 10.1093/aob/mcj004

Teixido, A. L., and Valladares, F. (2014). Large flowers tend to be short-lived in Mediterranean ecosystems: insights from three Cistus species. Plant Biosyst. 148, 1211-1220. doi: 10.1080/11263504.2014.948095

Waterman, R. J., and Bidartondo, M. I. (2008). Deception above, deception below: linking pollination and mycorrhizal biology of orchids. J. Exp. Bot. 59, 1085-1096. doi: 10.1093/jxb/erm366

Western, D. (1979). Size, life history and ecology in mammals. Afr. J. Ecol. 17, 185-204. doi: 10.1111/j.1365-2028.1979.tb00256.x
Westoby, M., and Wright, I. J. (2003). The leaf size - twig size spectrum and its relationship to other important spectra of variation among species. Oecologia 135, 621-628. doi: 10.1007/s00442-003-1231-6

Wyatt, R. (1982). Inflorescence architecture: how flower number, arrangement, and phenology affect pollination and fruit set. Am. J. Bot. 69, 585-594. doi: 10.1002/j.1537-2197.1982.tb13295.x

Yan, F. X., Tian, F., Jiang, Y. L., Luo, Z. Q., and Wang, L. H. (2017). A new Paphiopedilum cultivar 'GZSLKY Youyou'. Acta Hortic. Sin. 44, 1221-1222. doi: 10.16420/j.issn.0513-353x.2016-0740

Yang, D., Niklas, K. J., Xiang, S., and Sun, S. (2010). Size-dependent leaf area ratio in plant twigs: implication for leaf size optimization. Ann. Bot. 105, 71-77. doi: 10.1093/aob/mcp262

Yu, X. H., Luo, Y. B., and Dong, M. (2008). Pollination biology of Cymbidium goeringii (Orchidaceae) in China. Acta Phytotax. Sin. 46, 163-174. doi: 10.3724/SP.J.1002.2008.06203

Zhang, S. B., Guan, Z. J., Sun, M., Zhang, J. J., Cao, K. F., and Hu, H. (2012). Evolutionary association of stomatal traits with leaf vein density in Paphiopedilum, Orchidaceae. PLoS One 7:e40080. doi: 10.1371/journal. pone.0040080

Zhang, S. B., Yang, Y. J., Li, J. W., Qin, J., Zhang, W., Huang, W., et al. (2018). Physiological diversity of orchids. Plant Diversity 40, 196-208. doi: 10.1016/j. pld.2018.06.003

Zhang, F. P., Yang, Y. J., Yang, Q. Y., Zhang, W., Brodribb, T. J., Hao, G. Y., et al. (2017). Floral mass per area and water maintenance traits are correlated with floral longevity in Paphiopedilum (Orchidaceae). Front. Plant Sci. 8:501. doi: $10.3389 /$ fpls.2017.00501

Zotz, G., and Winkler, U. (2013). Aerial roots of epiphytic orchids: the velamen radicum and its role in water and nutrient uptake. Oecologia 171, 733-741. doi: $10.1007 / \mathrm{s} 00442-012-2575-6$

Conflict of Interest: The authors declare that the research was conducted in the absence of any commercial or financial relationships that could be construed as a potential conflict of interest.

Publisher's Note: All claims expressed in this article are solely those of the authors and do not necessarily represent those of their affiliated organizations, or those of the publisher, the editors and the reviewers. Any product that may be evaluated in this article, or claim that may be made by its manufacturer, is not guaranteed or endorsed by the publisher.

Copyright (c) 2021 Feng, Zhang, Huang, Hu and Zhang. This is an open-access article distributed under the terms of the Creative Commons Attribution License (CC BY). The use, distribution or reproduction in other forums is permitted, provided the original author(s) and the copyright owner(s) are credited and that the original publication in this journal is cited, in accordance with accepted academic practice. No use, distribution or reproduction is permitted which does not comply with these terms. 